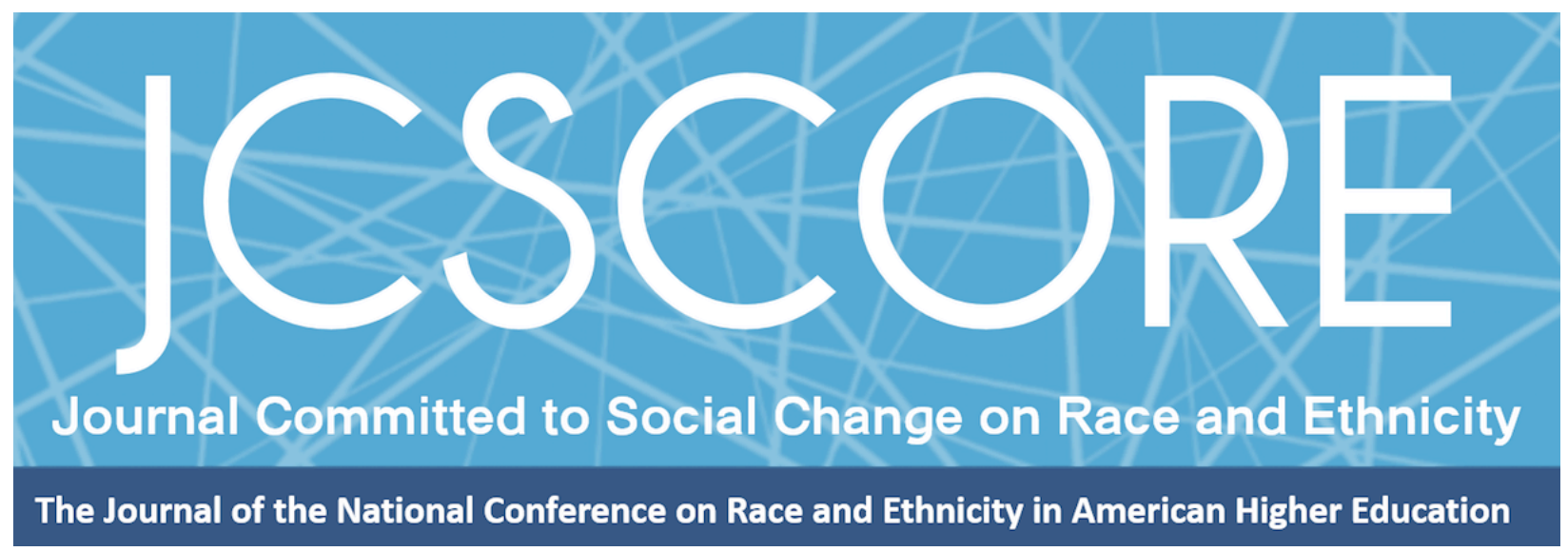

\title{
“WHO'S GOT BARS?”: REMIXING INTERGROUP DIALOGUE PEDAGOGY THROUGH HIP-HOP FEMINISM
}

\author{
Wilson Okello \\ University of North Carolina - Wilmington
}

Journal Committed to Social Change on Race and Ethnicity

Volume 6, Issue 2 | 2020

\section{Copyright and Open Access}

(c) 2020 Wilson Okello

\section{(c) (i) (2)}

This work is licensed under a Creative Commons Attribution-NonCommercial-ShareAlike 4.0 International License. Permission of the authors is required for distribution and for all derivative works, including compilations and translations. Quoting small sections of text is allowed as long as there is appropriate attribution and the article is used for non-commercial purposes.

The Journal Committed to Social Change on Race and Ethnicity (ISSN 2642-2387) is published by the National Conference on Race and Ethnicity (NCORE), a production of the University of Oklahoma, in partnership with the University of Oklahoma Libraries. 


\title{
“Who's got bars?": Remixing Intergroup Dialogue Pedagogy through Hip-Hop Feminism
}

\author{
Wilson Okello \\ University of North Carolina - Wilmington
}

\begin{abstract}
Hip-hop culture serves as a space to correct, prescribe, make known, and show up. Additionally, it offers its users opportunities to do what other spaces cannot, and that is to present a remix of a previously accepted script. Reintroduction can help Black lives, survive, dismantle, and escape systems of thinking that render them invisible and unheard. In this conceptually grounded manuscript, I discuss intergroup dialogue (IGD), with particular attention to IGD pedagogy. Though an important pedagogical strategy in and outside of higher education, IGD pedagogy may be operating to stifle the full expression of Black participants. By way of intervention, I point to possibilities within hip-hop feminism and hip-hop aesthetics to assist educators and facilitators in reimagining IGD pedagogical practice.
\end{abstract}

I often look back on that moment and muse over what compelled me to get up in front of my Black World Studies 151 class and rap 8 bars-needless to say this happened on the very first day of my freshman year of college. Growing up, I had always been introverted, shy, and painfully awkward. It goes without saying that public speaking or giving performances of any variety has never been my strong suit. Yet when given the opportunity to share whatever knowledge I possessed in any subject, I...found enough resolve to push my anxieties aside and speak in spite of my shaky voice and fast-beating heart. On the day that Wilson asked for someone to volunteer and share whatever bars came to mind, I honestly cannot relay what I was thinking, except that I had a perfect sample to present...

The above italicized reflection, is the meditation of a former student, who, unknowingly, changed the complexion of a semester in eight lines. Christyna sat in the front row, seemingly following the instruction that many Black students are given when they attend classes in higher education. The maneuver to make one's body visible seems to fit a hidden curriculum—a survival guide—-to ensure that Black students do not go unrecognized in historically white spaces. I saw Christyna, however, and the other Black 
Journal Committed to Social Change on Race and Ethnicity | Volume 6, Issue 2 | 2020

students who lined the front row and was determined for the rest of their peers to both see and hear them. As I read back over Christyna's words above, I was drawn to the notion that she possessed something to say and that all she needed was the opportunity for expression.

Western rationality, however, does not always have the same agenda with the voices of minoritized people. Following the logics of Enlightenment rationality, which calls for the dispassionate, objective pursuit of truth through order and control (Baszile, 2015; Chabal, 2012; Smith, 1999), Black and Indigenous People of Color's (BIPOC) ways of knowing and being are misunderstood, if not ignored all together as a formal practice of democratic exchange. This class (Wilson) I told myself, needed to be different.

While reviewing the syllabus on the first day of class, I explained my expectations around class discussion. Likely different from the ways first-year students have been trained to share information, I told them that we would be using a hip-hop aesthetic known as the cypher as our dialogic medium. I turned to hip-hop and the use of the cypher as pedagogy, fundamentally, because it broke from mainstream discourses of rational exchange in the academy (Baszile, 2015). Borne from my years of teaching and facilitation in higher education, I am increasingly alarmed by the rational sensibilities that guide exchange in the classroom, particularly as it relates to identity. This underpinning led me to ask, of what use is it for Black people to bring forward stories and experiences when there is no epistemic base upon which to validate and honor them? 
Journal Committed to Social Change on Race and Ethnicity | Volume 6, Issue 2 | 2020

\section{Allow Me to Reintroduce Myself}

Definitively, hip-hop has always existed as an epistemic project bent on definition for Black lives in a Western, United States cultural context (Rose, 1994, 2008). Hip-hop serves as a space to correct, prescribe, make known, and show up (Chang, 2006;

Durham et al., 2013; Morgan, 1999). Additionally, it offers its users opportunities to do what other spaces cannot, and that is to present a remix of a previously accepted script. As Black lives are expected to subscribe to particular ways of knowing and being in educational contexts, the notion of a remix can help Black lives, survive, dismantle, and escape the systems of thinking that render them invisible and unheard. Hip-hop feminism in essence is a remix of second-wave Black feminism that functions to "provide a political education and tools of critical analysis" (Peoples, 2008, p. 29). Building on the work of Black feminism (Collins, 1990; Davis, 1981; hooks, 1990; Lorde, 1984), hip-hop feminism is a form of radical inquiry that looks to and employs hip-hop aesthetics and epistemologies in the everyday lives of Black women and girls (Pough et al., 2007; Durham et al., 2013).

Furthermore, as a medium of responsiveness, hip-hop, broadly, and Black feminisms ${ }^{1}$ afford participants with the space to build and develop ideas that respond to a cultural context. On this, the first day of the semester, at an historically white university, in front of 39 new students (most of whom were white), Christyna responded to my inquiry, "who's got bars?," in a manner that made room for cogenerative exchanges (Petchauer, 2011) to occur. Cogenerative, here, describes the ways Christyna's contribution disrupted deeply rooted myths of Black women as non-knowers

\footnotetext{
${ }^{1}$ I use the plural form of feminism to honor the larger Black feminist canon that includes shifts and evolving iterations of the foundational term "Black feminism."
} 
Journal Committed to Social Change on Race and Ethnicity | Volume 6, Issue 2 | 2020

and unintelligible. In doing so, she gave sight and permission to a style of speaking and participation that might otherwise not exist in a formal classroom setting. This does not suggest that her peers believed that they needed to sound or share like Christyna; rather, the moment deposited new possibilities into the course archive for how differing voices would be valued. This cogenerative exchange mimics the hip-hop aesthetic known as the cypher (Alim, 2004; Chang, 2006; Kline, 2007), the cultural referent that would frame teaching and learning in this course.

Hip-hop cultural modes are at their height in the communal event known as the cypher. This complex matrix of cultural modes converges in a linguistic-cultural activity (Alim, 2004). Within this discursive speech event, the body is invited into full emotionality through word-creations, dialoguing, kinesics, metaphoric and hyperbolic language, designed to push participants out of their comfort zones in order to sharpen their skill set among a circle of critical audience observers. Moreover, Alim (2004) discussed cyphers as "innovative formats for battling (the ritual of rhyming informed by the physical arrangement of hip-hop) that break from traditional versions of democratic exchange that are linear, apolitical, and dispassionate" (p. 552). The cypher reframes dialogue as a non-linear and embodied social epistemology.

Lifting up Christyna's in-class experience, which demonstrates the potential of hip-hop feminist politics, and the cypher, this manuscript contributes to the literature on intergroup dialogue (IGD) by theorizing on the potential of a hip-hop feminist informed cypher. Specifically, I am interested in how hip-hop feminism might strengthen IGD pedagogy, allowing it to fully actualize its intended goals of cross-cultural engagement and communication in a manner that centers Black livelihood. In what follows, I ground 
Journal Committed to Social Change on Race and Ethnicity | Volume 6, Issue 2 | 2020

the need for this conceptual analysis in the overrepresentation of whiteness in higher education curricula and the disappearance of Black women and girls' ways of knowing in educational contexts. Before doing so, I offer a brief interlude on my positionality as it relates to this project.

\section{Miseducation}

In 1998, artist Lauryn Hill released the album The Miseducation of Lauryn Hill. Among other things, the album sought to critique systems of power and control. Furthermore, the album was a timely contribution to the counter-storytelling project that Black lives have long advanced inside and outside of educational contexts (Baszile, 2015). Instructive in her approach, Hill talked back to Enlightenment rationality (Smith, 1999) in a number of ways. First, she did not feign neutrality, objectivity, or pretend to be apolitical. Hill embraced a way of knowing that lifted bodies as both thinking and feeling entities; she reminded listeners that bodies are raced, gendered, sexualized and placed in relation to one another; she demanded that listeners hear and respond to social differences in the work to reimagine relationality in the world.

Furthermore, Hill (1998) recognized that curriculum can be both a humanizing and dehumanizing force in and beyond educational contexts, which refers to the profound injection of classroom references in the album. At the core of how knowledge is distributed, regulated, and organized, curricula and their enforcing pedagogies, have onto-epistemological implications such that they determine how individuals view and, ultimately, understand themselves in the world. In response, scholars have challenged whiteness in terms of its institutional structure, conceptual genealogies, and bibliographical narrowness (Tuck \& Gaztambide-Fernandez, 2013). Under scrutinized, 
Journal Committed to Social Change on Race and Ethnicity | Volume 6, Issue 2 | 2020

however, are the ways whiteness may seep into cultural pedagogies and practices and reinforce expectations of Western, United States citizenship (Baszile, 2008; Smith, 1999). One of those culturally rooted pedagogies is IGD.

\section{Miseducation and Me}

Miseducation, as a Black feminist project, centered healing. I am cognizant that while the album certainly was a critique of larger systems of power and oppression, it was also a response to the pain inflicted on Black women by Black men. As a Black cisgender man, I recognize and own my role in the power structures that necessitated her testimonies. I work, however imperfectly, with Black feminisms in this text both in appreciation of Hill and the lessons I am learning from Black feminisms, and as a way to think with their intellectual projects toward a healing praxis that advances the livelihood Black women. Furthermore, as the instructor of the course and curator of the moments under investigation in this manuscript, I am keenly aware that my analysis may miss the mark, potentially make a spectacle of Christyna, and cause harm, given the limitations of one cishet man's readings. My hope is that where misinterpretations exist, they do not undermine the potentiality of Christyna's brilliance. Where there are points of agreement, let them belong exclusively to Christyna's hip hop feminist utterances and the graciousness with which she shared them with her peers and me.

\section{Intergroup Dialogue as Pedagogy}

IGD is a layered process, but lifts three important components to its pedagogy: Structured Interaction, Active and Engaged Learning, and Facilitated Learning Environments (Nagda et al., 2009). To both critique and extend this work, I foreground hip-hop feminism in an effort to enlarge educators' understandings of three themes 
Journal Committed to Social Change on Race and Ethnicity | Volume 6, Issue 2 | 2020

central to a hip-hop feminist project: representation, embodiment, and alternative modes of critical engagement (see Durham et al., 2013; Peoples, 2008; Pough, 2003). A deeper understanding of these core ideals can assist educators and facilitators in tuning in to the complexity of Black lives in educative spaces, such that they can see, hear, and listen to the embodied knowledge by which they make themselves known (Brown \& Kwakye, 2012). Additionally, if IGD pedagogy is to be relevant and responsive to the changing society, it is important that it dialogue with cultural practices already at work in earnest. In the next sections, I discuss intergroup dialogue's structure and goals, and identify places of intervention.

\section{Brief Review of IGD}

Broadly defined, IGD is a person-to-person experience predicated on the exchange of discourse. At its core, it seeks to facilitate cross-cultural engagement between different social identity groups over a sustained period in order to generate new understandings and insights about one another (Schoem \& Hurtado, 2001; Zúñiga et al., 2007). Additionally, the IGD model determines to explore ways in which diverse peoples can come together to advance the work of equity and justice. There is an ethos of social responsibility that undergirds the practice of IGD as an approach to diversity and multicultural education, dependent primarily on the vehicle of conversation and collaboration. Distinguished by its critical-dialogic approach to exploring commonalities and differences between social identity groups, intergroup dialogue fosters a critical examination of the impact of power relations and social inequality on intergroup relations (Schoem \& Hurtado, 2001; Zúñiga et al., 2007). Dialectically different from the notions of learning that favor banking concepts (Freire, 1970), that see and view lives as 
Journal Committed to Social Change on Race and Ethnicity | Volume 6, Issue 2 | 2020

empty receptacles to be filled by a knowledgeable repository or as subjects of content assimilation, dialogue promotes active and generative modes of learning (Schoem \& Hurtado, 2001). The aspiration of education pioneers was that dialogue could serve as the practice of deliberate democracy, as they "sought to foster in learners the capacity and disposition for participation" in the public sphere (Zúñiga et al., 2007, p. 5).

Moreover, intergroup dialogue was historically conceptualized as a pedagogical tool to deal specifically with racial strife and conflict surfacing on college campuses. According to Maxwell et al. (2011), "the core practices of IGD involve students exploring their own and others' social identities in the context of broader patterns of systemic inequalities" (p. 163). In the classroom and outside of it, the exploration of identity is central to building meaningful intergroup relationships. Further, IGD may include "fostering an environment that enables participants to speak and listen in the present while understanding the contributions of the past and the unfolding of the future" (Dessel \& Rogge, 2008, p. 211). Facilitators assist in creating these environments by giving attention to factors such as location for the dialogue, the subject matter to be discussed, the ground rules, and the designed plan for engagement (Dessel \& Rogge, 2008).

\section{Repeating the Refrain: Critique of IGD}

Though useful in creating opportunities to dialogue about and across differences, identify common needs and goals, and surface varying perspectives (Ross, 2000), intergroup dialogue is framed in and through a constructivist paradigm of meaning making, which supports the social construction of identity and posits that individuals' experiences should be centered in discussions of meaning making. Particularly, the 
Journal Committed to Social Change on Race and Ethnicity | Volume 6, Issue 2 | 2020

emphasis on structured engagement and outcomes (Gurin et al., 2013; Maxwell et al., 2011; Nagda et al., 2009; Zúñiga et al., 2007), may restrict the ability for alternative ways of being to surface in dialogue, thereby hindering meaning making opportunities for some participants. Hip-hop feminism is concerned with the lived reality of women and girls of color (Rose, 1994; Morgan, 1999; Pough, 2003), but more so "regimes of racialized representation that shape social identity and gender relations and with how these regimes structure the ways Black women and other women of color are made intelligible" (Durham et al., 2013, p. 727). Shifting toward a critical paradigm for meaning making, the infusion of hip-hop feminism strengthens the ability of IGD to be responsive to the needs of Black participants.

Breaking with rational underpinnings, scholar, theorist, and hip-hop feminist Gwendolyn Pough ${ }^{[1]}$ (2003) discussing the nature of existing in the public sphere wrote that Black participants have had to reshape the "public gaze in such a way as to be recognized as human beings — as functioning and worthwhile members of society—and not be shut out of or pushed away from the public sphere" (p. 17). Pough (2003) added that a public pedagogy borrows the energy of the $M C$ to center critical issues in the public sphere. The indication here is that a public pedagogy is also a form of knowledge production that exchanges and transmits resources from diverse sites of knowledge. In attempts at rationality (Baszile, 2015)—dispassionate, structured, organized approaches to the sharing of knowledge-IGD may establish a mode of civil authority over the experiences of Black lives, thereby controlling their imagination and possibilities. For some, this procedure may inhibit what Freire (1970) calls critical consciousness, or "the means by which men and women deal critically and creatively 
Journal Committed to Social Change on Race and Ethnicity | Volume 6, Issue 2 | 2020

with reality and discover how to participate in the transformation of their world" (p. 34). It is this potential failure of dialogue to account for the stark realities materialized through Black lives, the very site, perhaps, where the oppressed draw their greatest strength (hooks, 1990), which represents this pedagogy's limitation. Efforts to maintain control, comfort, and confidentiality—or what Yawo Brown (2015) has termed polite white supremacy, stifle the possibility of pedagogy. Building on this emphasis, I point to the possible interventions available with hip-hop feminist aesthetics to transform what Lorde (1984) would call the tools that function from the master's logic.

Remixing dialogue as a public pedagogy (Pough, 2003), hip-hop feminism allows educators and facilitators to center the sociopolitical (Okello, 2018), or the conditions by which history, in its mental, social, spiritual, legislated, and spatial utterings, is mapped on to the present as the grounds of everyday existence for Black lives. Moreover, it replaces white epistemologies or rational practices (Baszile, 2015) focused on routine and appeals to control that invert the full participation of marginalized lives in the learning arena. To demonstrate this break with routine and claim to full participation, the next section returns to Christyna's 8-bar freestyle and reflection on that moment. Her testimony (Baszile, 2008) contextualizes my use of hip-hop feminism as an intervention in IGD pedagogy. Before doing so, I offer a review of hip-hop feminism.

\section{A Hip-Hop Feminist Analysis}

An outgrowth of second-wave Black feminism, hip-hop feminism is: a cultural, intellectual, and political movement grounded in the situated knowledge of women of color from the post-civil rights or hip-hop generation who recognize culture as a pivotal site for political intervention to challenge, resist, and mobilize collectives to dismantle systems of exploitation. (Durham et al., 2013, p. 72) 
Journal Committed to Social Change on Race and Ethnicity | Volume 6, Issue 2 | 2020

As such, hip-hop feminism situates the body as a site of knowledge (Durham et al., 2013). According to Johnson (2001), to "pursue an epistemology rooted in the body-as a theory in the flesh—spawns a kind of identity politics that acknowledges difference within and between particular groups" (p. 9). In this way, Christyna's verse does important onto-epistemological intervention as she works to reframe the ways Black women are read and interpreted in and beyond educational sites. One of the fundamental tenets of dialogue is that it often asks people, particularly minoritized people to suspend the full weight—historical, social, political—of their identities in order to manage a conversation whereby participants can palpably engage with pieces of their experience (Baszile, 2015). Black feminism challenges this convention, opting for a decidedly fuller picture that will not reduce multiple identities into a monolithic subgroup or claim a narrow compartmentalization. Hip-hop feminism demands, as Joan Morgan (1999) calls it, "a feminism brave enough to fuck with the grays" (p. 59). Critiquing earlier feminist movements that called for drawing lines in the sand along the lines of identity and sexual politics, Morgan is "refusing easy and essentialist political stances about what is right or wrong" (Durham et al., 2013, p. 723). Hip-hop feminist pedagogy (HHFP) as explained by Ruth Nicole Brown (2009) is one that demonstrates an appreciation for creative production and possibilities expressed through language and art. HHFP centers a Black feminist standpoint while incorporating the knowledges inherent in hip-hop, pedagogy, and feminism, therefore making it malleable and selfadjusting. Distinctly, HHFP "stages the political through performance based cultural criticism and is located and interpreted through communities" (p. 4). In what follows, I share Christyna's reflection on the course and my analysis of her reflection. 
Journal Committed to Social Change on Race and Ethnicity | Volume 6, Issue 2 | 2020

\section{Who Do You Think You Are?}

Hi Dr. Okello

I just wanted to briefly message you to say thank you for a phenomenal semester! This course was definitely my favorite out of all of my other classes, and it's largely because I had you as a teacher. What separated this class from the rest of the ones I've taken this year--as well as some from high school--was that after every single session, I wanted to do something with the knowledge I had acquired and engage in discussion with my relatives, coworkers, and peers. Coming to class was like a breath of fresh air and I thoroughly enjoyed being a partaker of the several conversations, as they helped me to understand a plethora of other perspectives including my own with regard to how I view the world in which we live in... I definitely feel empowered.

Thank you for everything, and best of luck to you!

Christyna

I received the preceding email at the end of the fall semester, 2016. Both

humbled and curious about what, specifically, led Christyna to share this sentiment, I asked her if she would be willing to talk more about the experience. Our conversation was instructive in several ways, but as mentioned above, Christyna and I were drawn back to the first day of class. Sensing that my pedagogical approach was distinct from what she has encountered, I asked if she would elaborate on the following questions: How did you feel about the invitation to share? How did you feel about the way you were received? What did it teach you about me as the instructor? How did you feel about the class after that moment and what it would be like to engage? Graciously, Christyna agreed, writing:

I remember the moment like it happened yesterday: I raised my hand, stood up from my desk, and began to let the words flow:

You don't know the price that the airtime brings

When you get so high up it gets harder to breathe

Climbing on, and they catch onto the breeze of my tailwind

But I just keep flexing my wings

Like l've been reached the top of the peak

Top of the hill, whole world at my feet

Cuz I stayed on my grind and I kept it low-key

Now I lead the pack and they all follow me 
I will admit though, after I sat down, and once the applause from my classmates died down, it began to register that I literally had just given a free rap performance in front of several other students. I felt a mixture of exhilaration and embarrassment, realizing that both the black and white students could perceive me as the awkward black girl in sweats, sneakers, and a dad cap that chose to "show off" on the first day of school. While I was proud of myself for taking a risk and branching out of my comfort zone, I also cringed at this sudden flash of boldness. At that moment, it felt like my subconscious self-responded, asking me: "Who do you think you are?"

At the time, I gave little thought to the extent of the effect that my performance had on the rest of the semester. I recall a conversation I had with Wilson later on during a meeting in my junior year, in which we both reflected over how my actions back then set the tone for the next 14-weeks. There seemed to be a certain vulnerability shared between myself and my classmates, through which we felt safe to express our opinions and values in a way that I had never seen before. To this day, I have yet to experience a college course that has given students that much freedom to engage and grapple with controversial issues like we did in that BWS 151 class. I learned so much about myself that semester. It was refreshing to be able to experience a professor that opened my eyes to learning about true history. To say that the course changed my life might be an understatement.

As I look back on the first day of class, I am grateful for that opportunity and experience. That moment taught me about myself, and about Wilson. I learned that he is the type of instructor that facilitates and encourages student development through self-expression of whatever means; even if that includes an 8-bar freestyle on the first day of school. While some might find the moment corny, I promise that that moment opened the door for a new depth of learning that my classmates and I will treasure forever.

Christyna's reflection, and more particularly, her decision and verse on the first day of class, evidence variables of a hip-hop feminist praxis. First, Christyna's reflection encapsulates representation, whereas, representation is a result of, and response to, one's body interacting in and with an environment. Representations are insightful, innovative tactics that attempt to negotiate one's positionality, rights, and freedoms in a truncated space. Generally, the classroom site has been unresponsive and hostile to Black girl literacies (Hill, 2016b; Shange, 2019). Christyna placed her body on display as a pedagogical act of refusal against circulated histories that actively worked to 
Journal Committed to Social Change on Race and Ethnicity | Volume 6, Issue 2 | 2020

silence her, and in doing so, generated additional possibilities for Black women to show up as knowers.

Related to embodiment, Christyna's verse prioritizes the body as an epistemic, ontological, social, spiritual, and spatial entity, always and already mediated by history (Hill, 2016a). Her decision and verse sit in the space between belonging and exile (Shange, 2019), as she stripped through repressive meanings (Spillers, 1987) that have been constructed over time. Foregrounding the body, she meditates on "breath" and the labor expected of her (and other Black women) in pursuit of her goals. In and against these histories, she poignantly (re)imagines a world where Black women exist on top, "world at my feet," inviting her peers and professor to consider this possibility in relation to the content we would be reviewing throughout the semester. Finally, Christyna's verse mobilized critical engagement, as it stretched beyond rational discourses and centered diverse literacies. Again, as classroom sites have enacted violence on Black girl and woman expressiveness, relegating them to stereotypical tropes of respectability, as Christyna, "stood up from my desk, and began to let the words flow," she insisted on being read and understood through a different register.

Acts of transgression. Instead of a reductive approach to the identity question, a hip-hop feminist approach ponders how the amalgamation of subjectivity and agency may propel material people into action (Durham, 2014; Freire, 1970). The implicit meaning in this theorizing is that individuals do not live single-issue lives, and must, therefore, adjust our thinking accordingly (Davis, 1981; Lorde, 1984). Here, Christyna's decision to insert the self into conversation is an example of how Black girls make space for themselves against disciplining logics that do not otherwise recognize them. 
Journal Committed to Social Change on Race and Ethnicity | Volume 6, Issue 2 | 2020

Following Hill (2016b), Christyna's decision and verse were acts of transgression that functioned to create an identity that spoke to who she was and who she wanted to be. That she gave little thought to the performance in the moment, seems to reflect what Brown (2013) might call Black girl genius, in that her un-meditated decisions are part of a larger project of way-making.

Moreover, educational processes remain steeped in Western/European rationality, heteropatriarchy, sexism, and racism (Baszile, 2015). These forces converge to shape how society sees, doesn't see, and ultimately, how Black women ought to behave in the world. Hill (2012), talking back to these processes, explained:

I write to speak/To be heard/To write myself/and others like into space...to claim ownership of myself, see my voices, and change the world around me. I write to tell the story of my body as presence, identity performance, and knowledge. ( $p$. 16)

Similar to Hill (2012), the insistence of Christyna's need to share is birthed out of, and in direct relationship to the way schooling is enlivened with "historical stereotypes of Black femininity and monolithic portrayals of Blackgirl's ways of being" (Hill, 2016b, p. 281). Though stretching the ways that one is seen and understood are critical, to embody alternative ways of being is to compete with familiar discourses of rationality. Christyna points to this tension saying:

While I was proud of myself for taking a risk and branching out of my comfort zone, I also cringed at this sudden flash of boldness. At that moment, it felt like my subconscious self-responded, asking me: 'Who do you think you are?'

Her language evidences the ways white supremacy penetrates our logics such that pedagogical attempts and agentic stands are routinely called into question both by the public and the self. Furthermore, Black femininity is continuously cramped into confines of respectability that disapprove of critical comportments. Thus, it should come as no 
Journal Committed to Social Change on Race and Ethnicity | Volume 6, Issue 2 | 2020

surprise that Christyna raised questions about her actions. Hip-hop feminism, in this way, roots as necessary an ability to speak to contradictions present in the material lives of people and examine the contested and complex ways women of color negotiate their decisions and employ self-esteem (Brown \& Kwakye, 2012). While imperfect, her decision and verse can challenge the fixed notions mapped onto Black women.

The disorientation that Christyna experienced following her act, lifts up both the potential and complexity of a hip-hop feminist intervention as one must continuously grapple with the learned behaviors that police the space, time, energy, and movement of Black lives broadly, and Black women, in particular. Furthermore, there appears to be the recognition that the curricular experience was temporary, and that after 1 hour and 15 minutes, Christyna and her peers would have to retreat back into themselves. As such, Christyna's decision and verse abound in the grays (Morgan, 1999), inviting educators to ask, how might I normalize opportunities for Christyna's boldness, such that she and others might be able to incorporate a new praxis of living outside of the classroom?

\section{Hip-Hop Feminist Intervention on IGD Pedagogy}

The latter question gives way to what the Crunk Feminist Collective (CFC) (Durham et al., 2013), a group of hip-hop generation feminist scholars, term percussive feminism. Percussive feminism draws from the definition of percussion, which denotes, "the striking of one body with or against another with some degree of force, so as to give a shock; impact; a stroke, blow, knock, and from the affinity for percussion in Southern rap music" (Durham et al., 2013, p. 724). The CFC argues that percussive is "both disruptive and generative", and "allows for the creativity that ensues from placing 
Journal Committed to Social Change on Race and Ethnicity | Volume 6, Issue 2 | 2020

modes or objects of inquiry together that might not traditionally fit" (Durham et al., 2013, p. 724). Hip-hop feminism grounds its process of identity and subjectivity negotiation in a political praxis that speaks to material existence. Careful not to stand on or by destructive allegiances inherent within any identity grouping, hip-hop feminism disrupts totalizing and single-story narratives that can brand identity politics. In what follows, I discuss the ways hip-hop feminism can extend IGD pedagogy.

Remaking structured environments. Central to IGD pedagogy are structured interactions, which aim to "learn interdependently as [participants] practice listening, asking questions, exploring contentious issues, and making connections with others. With the help of facilitators, students develop guidelines for respectful dialogic engagement, including working with disagreements and conflicts" (Nagda et al., 2009, p. 2). These decisions, however, may be acting to foreclose discussions. Mirroring what Evelyn Brooks Higginbotham (1993) terms the politics of respectability_-" a range of strategies, largely regarding notions of honor, self-respect, piety, and propriety...to secure access to the public sphere" (p. 185), while generally productive, these politics also employ "tactics such as surveillance, control, and repression...succeeding in reinscribing systems of power" (Durham et al., 2013, p. 724). This is not to suggest that educators should not plan before they teach/facilitate (Quaye, 2012); rather, they ought to be mindful of how their structures privilege particular ways of being, and who that structure serves to benefit. A hip-hop feminist reframing of battling and the cypher, aesthetics within hip-hop, may disrupt these patterns.

Hip-hop feminism stretches and expands the cypher concept to one that hinges on consent and cooperation, and reclamation of voices, lives, and spirits, rather than 
Journal Committed to Social Change on Race and Ethnicity | Volume 6, Issue 2 | 2020

masculinist ideals defined by competition (Brown, 2009). Christyna captures this sentiment, writing, "There seemed to be a certain vulnerability shared between myself and my classmates, through which we felt safe to express our opinions and values in a way that I had never seen before." This sense of felt safety critiques the ways gender and the proximity to femininity can affect the perception of Black women and girls in educational contexts (Fordham, 1993). Christyna's attention to the freedom of expression and opinions sheds light on the messages Black women and girls receive to remain silent if they are to be deemed worthy of acceptance and support. Additionally, Christyna invokes the pronoun "we," suggesting, perhaps, that her verse was not just about her; rather, it appeared to provoke a sensibility among her peers about what was possible. In this way, the verse was not just for or about Christyna, but about shifting how the class might understand the Black women who sat alongside Christyna.

The expectation when you enter the cypher as a participant is that you come prepared to do something with the language, embodied and otherwise, that you have and in the same instance host a willingness to be held accountable for your articulations in real time. Learning experiences that operate from this center challenge the structured rituals and logics that define good practice in intergroup dialogue. Urgent within the cypher are truth telling styles and sounds that reflect the lives, loves, histories, hopes, and fears of artists (participants). These embodiments give way to what is known as kinetic consumption (Kline, 2007). This aesthetic refers to the fact that "hip-hop is meant to be felt and not just seen and/or heard" (Kline, 2007, p. 55). That is, a key feature of authenticity and appreciation in any hip-hop activity is when the audience or participants experience a deep resonation illustrated through some kinetic response. Moreover, 
Journal Committed to Social Change on Race and Ethnicity | Volume 6, Issue 2 | 2020

kinetic consumption (Kline, 2007) points to African centered epistemologies that regard affect and emotional experiences as critical and valid ways of meaning making (Akbar, 1984; Asante, 1988).

Transformational in its musical blend, the cypher advances what Chang (2006) calls polyculturalism, unlike multiculturalism, "which tends in practice to fix and essentialize cultures, it describes the way cultures influence each other like that of jazz quartet (inspiring and changing together)" (p. xv). This improvisational attribute possesses the fundamental capacity to color gray what were black and white perspectives. Agency, as the creative force that allows one to challenge, act upon, or change the world around them, occurs in the cyphers juxtaposition of sounds, voices, lives, and styles (Chang, 2006; Kline, 2007). As ideas are introduced/performed, they are deconstructed and reconstructed in ways that allow for richer, more complex, and expansive representations and understandings.

Composing active and engaged learning. The second primary component of IGD pedagogy calls for active and engaged learning. Specially, IGD pedagogy believes "course curricula include readings (historical, sociological, scientific, and narrative), didactic and experiential activities, writing assignments provide space for reflection and help students integrate their learning" (Nagda et al., 2009, p. 2). These practices, indeed, are capable of producing rich engagement; however, in such practices, there is a reliance on cognitive knowing over embodied knowing. Discourse, as is typically mediated in a Western context, is facilitated by and through the Cartesian thesis, which forces participants to confer only with cognitive thought processes as legitimate sources of knowledge, controlled for and reproduced through systems of power and oppression 
Journal Committed to Social Change on Race and Ethnicity | Volume 6, Issue 2 | 2020

(Baszile, 2015). Such absolute thinking implies that one is free from the bounds of subjectivity (e.g. affective, physiological, sense perception, temporality), calling for a mind and body split (Baszile, 2015). Hip-hop feminism is a rebuttal to the claim that to know occurs detached from, and independent of the knower, and subsequently rationalist forms of discourse that privilege rules and structure over the full expression of subjectivities (Brown \& Kwakye, 2012; Durham, 2014). Toni Cade Bambara, as recorded in Brown's (2009) review of Black girlhood, advocates for a reassessment of the body and confrontation with the normalized complicity that renders Black lives as fundamentally inferior and illegible, suggesting:

But that is of course, what we must demand of teachers who come into contact with our children-that they have to think more clearly and more honestly than they're trained to, too react more authentically to what they experience with the Black student rather than to what they think they know. (Brown, 2009, p. xvi)

Given this pronouncement, one ought to read Christyna's verse as an intervention on the many forms of violence that constrict Black women, which began before she stepped on campus and into the classroom. Education contexts, seeded in heteropatriarchy have trained Christyna and other Black women, broadly, on the politics of recognition. Herein, she was unwilling to allow the racialized and gender proclivities of her instructor(s), to unrecognize and erase her nuanced contribution.

More to the point, hip-hop feminism refashions the learning environment through multilayered totalizing expression (Alim, 2004). With multiple layers of call and varied avenues of response, occurring simultaneously and synergistically, the audience (witnesses/listeners) comes into conversation with the performers (participants). This experience builds off of the communicative strategy known as call and response (Smitherman, 1997), which stresses commonality and group exchange, as the audience 
Journal Committed to Social Change on Race and Ethnicity | Volume 6, Issue 2 | 2020

(witnesses/listeners) is fully engaged in the performance. To know is thus tied to and inextricably bound up in community, resisting the explicit focus on individualistic notions of meaning making (Petchauer, 2011; Smitherman, 1997). The expectation through multilayered expression is that one not only bears witness, but also participates in sense making. Christyna's decision and verse participates in these sense making possibilities and expands the realm of possible expression to include modes of discourse that are more consistent with the lives of Black women. The centrality of language and its delivery are crucial factors in a dialogic learning experience, as such, diverse methods are needed to excavate honesty.

Letting go in the learning environment. The final component of IGD pedagogy is facilitated learning environments. Thoughtful educators are crucial to successful facilitation. Quaye (2012) supports this, positing, good facilitators "strive to mitigate the power imbalances between themselves and students... co-construct ground rules... develop a keen ability to assess the environment of the classroom to ascertain students' levels of preparedness and developmental readiness for engaging in dialogues" ( $p$. 557). While important, unmonitored, this design reinforces a dangerous show of power as it faithfully commits to outcomes that support appearances held up on rationality and reason. In these cases, it is the responsibility of Black people to lead the privileged to the hopeful, yet fragile places, of freedom from guilt and presumed understanding. Brown (2009) seemingly agreed, advising, "we do not have a language that accurately describes what it means to work with Black girls in a way that is not controlling their bodies and/or producing white, middle-class girl subjectivities" (p. xv). Hip-hop feminism compels us to question the routinized instruction of dialogue pedagogy toward sensible 
Journal Committed to Social Change on Race and Ethnicity | Volume 6, Issue 2 | 2020

conclusions and secure senses of self. Discourse grounded in the materiality of the subjugated is less likely to arrive at oversimplified meditations and feel good stories of progress.

Alternatively, hip-hop feminism encourages "producing democratizing forms of knowledge that enable all of us to better understand the ways racialized sexuality is represented, performed, and policed in the United States and abroad" (Durham et al., 2013, p. 729). Christyna's verse did this work. In most classes, when I ask, "who's got bars?," students sheepishly smile and mumble to each other something to the effect of, "is he serious?" I typically retort in the affirmative, before moving into a general discussion of how a cypher works. I read Christyna's participation as much more than the response to a call; it was an invitation into how she wanted to be engaged - and subsequently how Black women and girls are generally not engaged. She left clues for me, as the instructor, and her peers in the verse, as noted above, while also expanding and democratizing the classroom space.

Democratizing forms can be seen in hip-hop feminism's evolving digital presence (Emdin \& Adjapong, 2018). Freeing up participants to share in new and profound ways socially "is not only evidence of the movement's relevance and strength but also reflects its continued interest in democratizing the creation and dissemination of knowledge as well as promoting open dialogues about issues important to communities of color" (Durham et al., 2013, p. 733)—an instantiation of public pedagogy (Pough, 2003). In the quest to establish the self and to define oneself in relation to others, these critical approaches are representative of the hip-hop aesthetic sampled consciousness. Definitions abound for this device, but at its core, it signals an incorporation of segments 
Journal Committed to Social Change on Race and Ethnicity | Volume 6, Issue 2 | 2020

from a previous body of work into a refashioned product (Chang, 2006). A sampled consciousness borrows the hip-hop aesthetic known as sampling, or the "practice by which a DJ or hip-hop music producer takes any part of previously recorded material and uses it to create new music in a new context and composition" (Petchauer, 2009, p. 967). A sampled consciousness is thus one that is created by the act of bricklaying stories, interactions, and observations in the piecing together of a self-concept. Either intentionally or unknowingly, our worldviews are the output of a consciousness beholden to flux and remix, consistent in its alternating, subtracting, choosing, and negotiation. This version of consciousness departs from IGD's conception as it lobbies for a continuous process of deconstruction and reconstruction (incomplete understanding) as an educational outcome. Our identities, and subsequently, consciousness is ever shifting, and in this regard should not anticipate that public exchanges, distributed by power relations, could lead to a place of complete knowing. There is importance in examining the origins of stereotypes and misinformation about the self and others, while delving into power, privilege, and oppression, through IGD.

\section{Hip-Hop Feminist Informed Praxis}

Hip-hop feminism can intervene on rational discourse— "a dispassionate, objective pursuit of the Truth through rational argument—as the best way to maintain order and control" (Baszile, 2015, p. 240). Principally, I am calling for a critique of the pedagogical expectations and standards that blot out the sensibilities of Black women and girls, and Black students, broadly, in favor of the linguistic supremacy, "or the unsubstantiated notion that one set of linguistic norms are inherently superior to the linguistic norms of other communities" (Alim, 2006, p. 66). With the following 
Journal Committed to Social Change on Race and Ethnicity | Volume 6, Issue 2 | 2020

recommendations, I theorize with hip-hop feminist praxis—representation, embodiment, alternative modes of critical engagement—and what I learned from Christyna's hip-hop feminist politics, to challenge approaches to intergroup dialogue that hem in the full range of expression and experiences of Black students, and provide some ideas for how to actualize a cypher.

Check yo self before you wreck yo self. Checkin yo self, before you wreck yo self, points to an individual's responsibility to mindfully examine what they are about to say or do. Hip-hop feminism pushes this method to see the self as connected to the larger community of learners and, thus, willing to be vulnerable about one's positions as regular practice. The need for vulnerability recognizes that one's shadows and silences can "wreck" not just the self, but the community within which one is situated. A gendered and racialized analysis of one's position will ask how one's pedagogical enactments reinforce the habits and cultural codes that stifle the potential of Black women and girls, and Black lives broadly. What literacies have been deemed as acceptable and what has been demonized and underappreciated? How have the patterns and insights coded in Black lives been misread and misinterpreted? How have I participated in the condemnation that allows for control, comfort, and safety to exist as the basis for intercultural communication? These questions are primarily for educators in preparation for engagement, but also a method of accountability to those with whom they are sharing space with. Responding to questions like these shifts the onus from students/participants as the ones responsible for generating productive exchange to the educator/facilitator. 
Journal Committed to Social Change on Race and Ethnicity | Volume 6, Issue 2 | 2020

Flipping the script. Flipping the script as a cultural adage references the ability to reverse the usual or taken-for-granted positions in a situation; it calls on the actor or speaker to invoke something revolutionary or unexpected. Educational socialization has made it such that our learning spaces are highly predictable. Well-constructed and thoughtful deviations from traditional methods can have a freeing effect on a student's cultural sensibilities as taught by Christyna's decision and verse. Moreover, Christyna's intervention models what is possible when we ask Black women and girls what they are experiencing and what they know. This begs the question, are educators providing space for Black women and girls to share what they might need from the classroom space and curriculum (Hill, 2016b) through a myriad of methods? As this occurs, the additional question surfaces: what are educators doing with what they learned and what do they still need to learn? For the sake of control and comfort, educators (thus modeling for students) often divorce themselves from the liberties of affect. Flipping the script demonstrates to fellow witnesses that as educators we are committed to the notion that being heard and included are only starting points to present and (re)present the self and others as products and producers of meaning, symbols, and history in their fullest sensory and social dimensions.

Testifyin. Testifyin suggests that subjectivity is grounded in the ability to respond, address, and make oneself real to others (Baszile, 2008). The cultural performances being summoned in these expressions of subjectivity are the ritual practices of giving testimony and bearing witness, the essence of representation and embodiment. One might understand testimony (Baszile, 2008) as the act of confirming, corroborating, attesting to, or providing substantial reasoning. The verb witness is 
Journal Committed to Social Change on Race and Ethnicity | Volume 6, Issue 2 | 2020

understood as the ability "to give evidence or be a spectator or auditor of something" (Henderson, 2014, p. 15). Seeing testimony and witnessing as interdependent, Henderson (2014) maintains that "speaking is fundamentally an act of witnessing, just as listening is fundamentally an act of bearing witness" (p. 16). I want to suggest then that testifyin, as representation and embodiment, can be a training ground for how Black women and girls orient themselves to the educational context writ large. In reflection Christyna wrote, "I learned so much about myself that semester," while discussing how refreshing it was to encounter the curriculum. What is not stated here, is that her testimony prompted the shifts that she came to enjoy. As the instructor of the course, witnessing Christyna urged me to create varied opportunities in our cypher to (re)present the self to the self, to one's peers, and to begin imagining what these representations could look like outside of the classroom, in internships, in their living arrangements and beyond. In another class meeting that same semester, I came to class feeling particularly heavy over recent incidents of racial violence. Instead of following the syllabus, I began the class with an original poem inspired by James Baldwins, The Fire Next Time (1963). After reviewing portions of the letter, I invited students to write their own letters and read them publicly. This time, when I asked, "who's got bars?", students responded in masse, volunteering to testify with their emotion filled letters.

As lives present with, observing, and participating in dialogic exchange, we take on the responsibility of being a witness to oneself, being a witness to the testimony of others, and being a witness to the process of testifyin. The following is an example of what testifyin might look like in a dialogic space, as Black girlhood scholar, Dominique 
Journal Committed to Social Change on Race and Ethnicity | Volume 6, Issue 2 | 2020

Hill (2012) talked back to oppressive educational logics, stating, "I have hesitated too many times and decided against saying my presence in this space, this place, this world. I am done hesitating, retreating, dismissing my importance" (p. 19). Offering readers/listeners insight into how curricula, perceptions, and the felt limitations she experienced because of the identities and subjectivities she housed, she struggles against them by testifyin and secondarily, provides witnesses evidence by which they should reimagine their lives.

\section{Possibilities For A Cypher}

The following sketch is an example of a cypher that centers representation, embodiment, and alternative modes of critical engagement:

1. Invite volunteers to participate. For example, in a class of 12 students, I asked for 5 volunteers. With volunteers and participants, move to an open space and form a circle. The selection of a space has political significance. I have done the exercise in the student union and around a seal on the campus grounds.

2. I ask them to recall an incident, epiphanic moment or occurrence that left a palpable impulse in you as it relates to the topic of silence. I enlarge the thought by asking, "How does it feel when are you silenced?" I instruct them to, without talking, think about a movement or action that embodies the feeling of silence and to take one minute to gather that movement or action to their mind. This instruction is designed to bring the body to bear on curricula, and in learning spaces, that privilege cognitive and verbal processing. Recognizing the risk involved in acting out silencing experiences, I instruct participants that they will have an opportunity vocalize, and talk through the movement or action following the performance. 
Journal Committed to Social Change on Race and Ethnicity | Volume 6, Issue 2 | 2020

3. One by one, I invite participants to silently act out their movement/action/gesture for their colleagues. I ask them to repeat the movement/action/gesture for about 1 minute. As the students individually perform, invite witnesses to observe and take in the bodily performances with the following questions: How is it being staged? What is the body doing during the performance? Is there provocative and evocative language/embodiment? What is said/communicated? What is not being said? Where and how do I resonate with the performance?

4. After each performance has been staged, invite the performers to respond to the following questions: How did it feel to perform your silence? What did you feel in your body? How was your body situated and read in the happening? What do you believe are the residual effects of silence and how did they show up in your performance?

5. After exploring and processing the performances, invite the volunteers to recall an incident, epiphanic moment or occurrence that left a palpable impulse on them as it relates to the topic of authenticity/moments where they felt powerful.

6. I follow the same procedure that I did for the performances of silence as a way to juxtapose the two moments.

This sketch is one rendering, as educators can adjust their questioning to accommodate developmental considerations. Additionally, this sketch can be adopted across course topics and disciplines. For example, during a qualitative inquiry lesson in a different course, I replaced the question on silence by asking participants to embody paradigms (e.g., post-positivist, constructivist, critical, etc.). This approach, complicated with racialized and gender critique, generated critical conversation about the paradigms, allowing participants to develop a different connection with the material. 
Journal Committed to Social Change on Race and Ethnicity | Volume 6, Issue 2 | 2020

\section{Outro: Conclusion}

A hip-hop feminist analysis of intergroup dialogue pedagogy challenges normative discourses and provokes the materialization of differential possibilities. As planted as it is in the grounds of realism concerning Black lives, the aesthetics discussed above, and the inspired principles of checkin yo self, flipping the script, and testifyin that support them are a method of imagination and exaltation of freedom. To embark on this journey of testimony and witnessing is to create opportunities for narrators to (re)constitute themselves as they reintroduce their always and already read, marked, interpreted bodies to witnesses. Educators, rightfully, should have questions about the epistemological limitations of calling on the body to be a site of educational praxis. To this, I want to suggest, that hip-hop feminist inspired work asks that one consider how Black women and girls, and Black people, in general, might (re)introduce themselves in the midst of complicated isms that converge with hardened representations that story students and their lives. The fundamental aim of this manuscript's critique and purpose is to lessen and eventually resolve the contradictions between what happens in educative spaces and the everyday life of our students.

Importantly, hip-hop is not perfect. As a project existing in a Western, racist, sexist, heteropatriarchy, hip-hop is not immune to the impositions of these systems, the manifestation of which deserves continued critique (Morgan, 1999; Rose, 2008). However, it is the ability to hold both a critique of interlocking systems of oppression and possibilities for varied forms of expression that captures the essence of hip-hop feminism. According to Morgan (1999), this approach epitomizes a functional feminism that is committed to keeping it real as hip-hop feminist consciousness allows for an 
Journal Committed to Social Change on Race and Ethnicity | Volume 6, Issue 2 | 2020

examination of how representations can be simultaneously empowering and

problematic. Marshaled as an art form, hip-hop in the manuscript was a stepping in, and declaration of the right to speak and be heard for Christyna and the many other Black lives in and beyond educational contexts. 
Journal Committed to Social Change on Race and Ethnicity | Volume 6, Issue 2 | 2020

\section{References}

Akbar, N. (1984). Afrocentric social science for human liberation. Journal of Black Studies, 14(1), 395-414.

Alim, H. S. (2004). 'Bring it to the cypher': Hip-hop nation language. In. M. Forman \& M.A. Neal. (Eds.), That's the Joint! The Hip-Hop Studies Reader, (pp. 530-563). Psychology Press.

Asante. M. K. (1988). Afrocentricity. Africa World.

Baldwin, J. The Fire Next Time. Dial Press.

Baszile, D. T. (2008). Beyond all reason indeed: The pedagogical promise of critical race testimony. Race Ethnicity and Education, 11(3), 251-265.

Baszile, D. T. (2015). Rhetorical revolution: Critical race counterstorytelling and the abolition of white democracy. Qualitative Inquiry, 21(3), 239-249.

Brown, R.N. (2009). Black girlhood celebration: Toward a Hip-Hop feminist pedagogy. Peter Lang.

Brown, R. N. (2013). Hear our truths: The creative potential of Black girlhood. University of Illinois Press.

Brown, R. N., \& Kwakye, C. J. (2012). Wish to Live: The Hip-Hop Feminism Pedagogy Reader.

Peter Lang.

Brown, Y. (2015). Medium. The subtle linguistics of polite white supremacy. https://medium.com/@YawoBrown/the-subtle-linguistics-of-polite-whitesupremacy-3f83c907ffff

Chabal, P. (2012). The end of conceit: Western rationality after postcolonialism. Zed Books.

Chang, J. (2006). Total chaos: The art and aesthetics of hip-hop. Basic Books.

Collins, P. H. (1990). Black feminist thought: Knowledge, consciousness, and the politics of empowerment. Unwin Hyman.

Davis, A. (1981). Women, race, and class. Random House.

Dessel, A., \& Rogge, M. E. (2008). Evaluation of intergroup dialogue: A review of the empirical literature. Conflict Resolution Quarterly, 26(2), 199-238.

Durham, A.S. (2014). Home with hip hop feminism: Performances in communication and culture. Peter Lang Publishing, Inc.

Durham, A.S., Cooper, B. C., \& Morris, S. M. (2013). The stage hip-hop feminism built: A new directions essay. Signs: Journal of Women in Culture and Society, 38(3), 721-737.

Emdin, C., \& Adjapong, E. S. (Eds.). (2018). \# HipHopEd: The compilation on hip-hop education: Volume 1: Hip-hop as education, philosophy, and practice. BRILL

Fordham, S. (1993). "Those loud Black girls": (Black) women, silence, and gender "passing" in the academy. Anthropology \& Education Quarterly, 32, 3-32.

Freire, P. (1970). Pedagogy of the oppressed. Herder and Herder.

Gurin, P., Nagda, B. R. A., \& Zuniga, X. (2013). Dialogue across difference: Practice, theory, and research on intergroup dialogue. Russell Sage Foundation.

Henderson, M.G. (2014). Speaking in Tongues \& Dancing Diaspora: Black Women Writing and Performing. Oxford University Press. 
Journal Committed to Social Change on Race and Ethnicity | Volume 6, Issue 2 | 2020

Higginbotham, E. B. (1993). The politics of respectability. Righteous Discontent:_The Women's Movement in the Black Baptist Church, 1880-1920, 185-230.

Hill, D.C. (2012). An unapologetic lyric: A warrior's battle for space in Education._In R.N. Brown and C.J. Kwakye (Eds.), Wish to live: The Hip-Hop feminism pedagogy reader. Peter Lang.

Hill, D. C. (2016a). What happened when I invited students to see me? A Black queer professor's reflections on practicing embodied vulnerability in the classroom. Journal of Lesbian Studies, 21(4).

Hill, D. C. (2016b). Blackgirl, one word: Necessary transgressions in the name of imagining Black girlhood. Cultural Studies $\leftrightarrow$ Critical Methodologies, 19(4), 275283.

Hill, L. (1998). The Miseducation of Lauryn Hill. Ruffhouse and Columbia Records. hooks, b. (1990). Yearning: Race, gender, and cultural politics. South End Press. Johnson, E. P. (2001). "Quare" studies, or (almost) everything I know about queer studies I learned from my grandmother. Text and Performance Quarterly, 21(1), $1-25$.

Kline, C. (2007). Represent!: Hip-hop and the self-aesthetic relation. [Unpublished doctoral dissertation]. Indiana University.

Lorde, A. (1984). Sister outsider: Essays and speeches. Crossing Press.

Maxwell, K. E., Chesler, M., \& Nagda, B. A. (2011). Identity matters. Facilitators' struggles and empowered use of social identities in intergroup dialogue. In K.E. Maxwell, M. Chesler, B.A. Nagda, \& M.C. Thompson (Eds.), Facilitating intergroup dialogues: Bridging differences, catalyzing change (pp. 163-178). Stylus Publishing.

Morgan, J. (1999). When chickenheads come home to roost: A hip-hop feminist breaks it down. Simon and Schuster.

Nagda, B. A., Gurin, P., Sorensen, N., \& Zúñiga, X. (2009). Evaluating intergroup dialogue: Engaging diversity for personal and social responsibility. Diversity \& democracy, 12(1), 4-6.

Okello, W.K. (2018). From self-authorship to self-definition: Remapping theoretical assumptions through Black feminism. Journal of College Student Development, $59(5), 528-544$.

Peoples, W. A. (2008). " Under construction": Identifying foundations of hip-hop feminism and exploring bridges between Black second-wave and hip-hop feminisms. Meridians: feminism, race, transnationalism, 8(1)19-52.

Petchauer, E. (2009). Framing and reviewing hip-hop educational research. Review of educational research, 79(2), 946-978.

Petchauer, E. (2011). I feel what he was doin': Responding to justice-oriented teaching through hip-hop aesthetics. Urban Education, 46(6), 1411-1432.

Pough, G.D. (2003). "Do the ladies run this...? Some thoughts on hip-hop feminism." In R. Dicker \& A. Pipemeier (Eds.), Catching a wave: Reclaiming feminism for the 21st Century, (pp. 232-243). Northeastern University Press.

Pough, G. D., Richardson, E. B., Durham, A., \& Raimist, R. (Eds.). (2007). Home girls make some noise: Hip-hop feminism anthology. Parker Publishing.

Quaye, S. J. (2012). Think before you teach: Preparing for dialogues about racial realities. Journal of College Student Development, 53(4), 542-562. 
Rose, T. (1994). Black noise: Rap music and Black culture in contemporary America. University Press of New England.

Rose, T. (2008). The hip hop wars: What we talk about when we talk about hip hop--and why it matters. Civitas Books.

Ross, M. (2000). Creating the conditions for peacemaking: Theories of practice in ethnic conflict resolution. Ethnic and Racial Studies, 23(6), 1002-1034.

Schoem, D. L., \& Hurtado, S. (Eds.). (2001). Intergroup dialogue: Deliberative democracy in school, college, community, and workplace. University of Michigan Press.

Shange, S. (2019). Black girl ordinary: Flesh, carcerality, and the refusal of ethnography. Transforming Anthropology, 27(1), 3-21.

Smith, L. T. (1999). Decolonizing methodologies: Research and indigenous peoples. Zed Books.

Smitherman, G. (1997). "The chain remains the same": Communicative practices in the hip-hop nation. Journal of Black Studies, 28(1), 3-25.

Spillers, H. J. (1987). Mama's baby, papa's maybe: An American grammar book. Diacritics, 17(2), 65-81.

Tuck, E., \& Gaztambide-Fernandez, R. (2013). Curriculum, replacement, and settler futurity. Journal of Curriculum Theorizing, 29(1), 72-89.

Zúñiga, X., Nagda, B. R. A., Chesler, M., \& Cytron-Walker, A. (2007). Intergroup Dialogue in Higher Education: Meaningful Learning About Social Justice: ASHE Higher Education Report, 4. John Wiley \& Sons. 